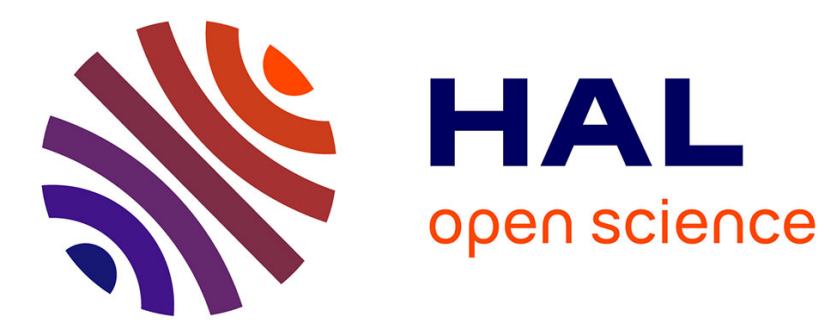

\title{
Coupled nonlinear vehicle control: Flatness-based setting with algebraic estimation techniques
}

Lghani Menhour, Brigitte d'Andréa-Novel, Michel Fliess, Hugues Mounier

\section{To cite this version:}

Lghani Menhour, Brigitte d'Andréa-Novel, Michel Fliess, Hugues Mounier. Coupled nonlinear vehicle control: Flatness-based setting with algebraic estimation techniques. Control Engineering Practice, 2014, 22, pp.135-146. 10.1016/j.conengprac.2013.09.013 . hal-00869053

\section{HAL Id: hal-00869053 \\ https://hal-polytechnique.archives-ouvertes.fr/hal-00869053}

Submitted on 2 Oct 2013

HAL is a multi-disciplinary open access archive for the deposit and dissemination of scientific research documents, whether they are published or not. The documents may come from teaching and research institutions in France or abroad, or from public or private research centers.
L'archive ouverte pluridisciplinaire HAL, est destinée au dépôt et à la diffusion de documents scientifiques de niveau recherche, publiés ou non, émanant des établissements d'enseignement et de recherche français ou étrangers, des laboratoires publics ou privés. 


\title{
Coupled nonlinear vehicle control: Flatness-based setting with algebraic estimation techniques
}

\author{
Lghani MENHOUR ${ }^{\mathrm{a}}$, Brigitte d'ANDRÉA-NOVEL ${ }^{\mathrm{b}}$, Michel FLIESS $^{\mathrm{c}, \mathrm{d}}{ }^{\text {, Hugues MOUNIER }}{ }^{\mathrm{e}}$ \\ ${ }^{a}$ Centre de Recherche STIC, IUT de Troyes, 9, Rue du Québec, 10000 Troyes, France \\ ${ }^{b}$ Mines-ParisTech, CAOR-Centre de Robotique, Mathématiques et systèmes, 60 boulevard Saint-Michel, 75272 Paris cedex 06, France \\ ${ }^{c}$ LIX (CNRS, UMR 7161) École polytechnique, 91128 Palaiseau, France \\ ${ }^{d}$ AL.I.E.N. (Algbre pour Identification \& Estimation Numriques), 24-30 rue Lionnois, BP 60120, 54003 Nancy, France \\ ${ }^{e}$ L2S (UMR 8506), CNRS - Supélec - Université Paris-Sud, 3 rue Joliot-Curie, 91192 Gif-sur-Yvette, France
}

\begin{abstract}
A combined nonlinear longitudinal and lateral vehicle control is investigated. Flatness-based nonlinear control and new algebraic estimation techniques for noise removal and numerical differentiation are the main theoretical tools. An accurate automatic pathtracking via vehicle steering angle and driving/braking wheel torque is thus ensured. It combines the control of the lateral and longitudinal motions in order to track straight or curved trajectories and to perform a combined lane-keeping and steering control during critical driving situations such as obstacle avoidance, stop-and-go control, lane-change maneuvers or any other maneuvers. Promising results have been obtained with noisy experimental data, which were acquired by a laboratory vehicle with high dynamic loads and high lateral accelerations.
\end{abstract}

Keywords: Intelligent transportation systems, coupled longitudinal/lateral vehicle control, flatness-based control, estimation, noise removal, numerical differentiation, algebraic techniques.

\section{Introduction}

The development and integration of intelligent systems for autonomous vehicles have received a lot of attention during the last decades. The aim of such systems is to reduce the driver's physical and mental workload (Tanaka et al., 2000). They have also been introduced to help the driver to cope with critical driving situations and make the vehicle more stable and steerable. A considerable effort has been achieved in order to develop several active and passive assistance systems, like Anti-Lock Braking System (ABS), Electronic Stability Program (ESP), Adaptive Cruise Control (ACC) and recently four wheel steering systems.

Vehicle dynamic control (VDC) has been widely discussed in the literature. Particularly, several studies on longitudinal and lateral control have been conducted and published. A major part of them deals with longitudinal or lateral control separately but rarely with a coupled one. Unfortunately, many critical driving situations involving the safe handling of vehicles require coupled control, and, such a strategy is rarely addressed in already published works. This remark is emphasized in surveys (Nobe \& Wang, 2001; Khodayari et al., 2010), where the authors give two lists of works concerning longitudinal and lateral

Email addresses: lghani . menhoureuniv-reims . fr (Lghani MENHOUR), brigitte.dandrea-novel@mines-paristech.fr (Brigitte d'ANDRÉA-NOVEL),

Michel.Fliessapolytechnique.edu \&

michel.fliessealien-sas.com (Michel FLIESS),

hugues.mounierelss.supelec.fr (Hugues MOUNIER) controllers, and point out that the longitudinal and the lateral controllers are addressed separately in the majority of cases.

Recently, a great many intelligent systems based controllers have been developed via lateral or longitudinal controllers. For lane keeping, lane-change maneuvers, pedestrian and obstacle avoidance, a lateral control is used (see, for example, Ackermann et al. (1995); Guldner et al. (1999); Tomizuka et al. (1999); Rajamani et al. (2000); Hatipoglu et al. (2003); Zheng et al. (2006); Plöchl \& Edelmann (2007); Cerone et al. (2009); Marino \& Cinili (2009); Menhour et al. (201); FernandezLlorca et al. (2011)). While, for stop-and-go, adaptive cruise control and platooning tasks, the longitudinal control is developed (see for example Rajamani et al. (2000); Mammar \& Netto (2004); Martinez \& Canudas-de-Wit (2007); Nouvelière \& Mammar (2007); Villagra et al. (2009)). In (d'Andréa-Novel \& Ellouze, 2001; Chou \& d'Andréa-Novel, 2005), a nonlinear global chassis controller is proposed which uses braking torques but without active steering control to follow desired trajectories in yaw rate and in longitudinal acceleration. In contrast, some works have dealt with the problem of comfort and improvements of ground vehicle handling through the joint braking and suspension control (see, for example, PoussotVassal et al. (2011)). Another approach that combines braking and steering control is also proposed in (Poussot-Vassal et al., 2011), where the longitudinal motion is considered as a varying parameter, and not as a state variable. See also (Zheng et al., 2006) for a similar approach.

Our study proposes a combined vehicle control scheme to cope with driving situations involving high longitudinal speeds 
and coupled longitudinal/lateral maneuvers. In fact, in (Mammar \& Netto, 2004; Nouvelière \& Mammar, 2007), the authors consider an integration of longitudinal and lateral controllers based on second order sliding mode control for vehicle low speed automation. In (Rajamani et al., 2000), a control law for the platooning maneuver is developed via an integration of a longitudinal and a lateral controllers based on $\mathrm{H}_{\infty}$ approach and gain-scheduling scheme respectively. For more details on these points, we refer the reader to the surveys due to Nobe \& Wang (2001); Plöchl \& Edelmann (2007); Khodayari et al. (2010).

Our vehicle control design rests on

1. flatness-based nonlinear control (Fliess et al., 1995, 1999) (see also Fuchshumer et al. (2005) for a related approach);

2. algebraic estimation and identification techniques (Fliess et al., 2008).

A 3DoF nonlinear vehicle model is also considered in order to establish such a controller. The algebraic techniques provide a good estimation of noisy signals derivatives, and are useful because sensors used in a real automotive application are generally low cost and their measurements are very noisy. Hence it is not easy to use such data in control applications.

The remainder of this paper is organized as follows. In the next Section, the flatness-based coupled nonlinear vehicle control problem is addressed. Section 3 presents a $3 \mathrm{DoF}$ and a $10 \mathrm{DoF}$ nonlinear vehicle model. Both models are respectively used for control design and performance tests. The vehicle coupling effects are also given in Section 3. Section 4 describes the control design steps and the proof of flatness. A short summary of the algebraic techniques and their application for the implementation of control law are given in Section 5. Section 6 presents simulation results using the noisy data acquired on actual roads under high longitudinal speeds and lateral accelerations. Conclusions and perspectives are found in Section 7.

See (Menhour et al., 2011, 2012) for a first draft of this paper.

\section{Problem statement}

The design and implementation of the coupled longitudinal and lateral vehicle control is one of the most challenging problems in the development of intelligent transportation systems. Such a controller plays a crucial role to carry out coupled maneuvers like automatic driving operations, pedestrian or/and collision avoidance system, lane-change maneuvers, lane keeping. For these reasons, this work deals with the design of a coupled nonlinear vehicle control in two steps:

- Step 1: derivatives and filtering of flat outputs using algebraic estimation;

- Step 2: flatness-based coupled nonlinear longitudinal and lateral vehicle control;

using the following theoretical tools:

- flatness property of a three degrees-of-freedom two wheels nonlinear vehicle model: flat outputs and the corresponding proof are detailed in Section 4;
- algebraic estimation techniques for denoising and numerical differentiation and their application for filtering and derivatives of flat outputs are given in Section 5.

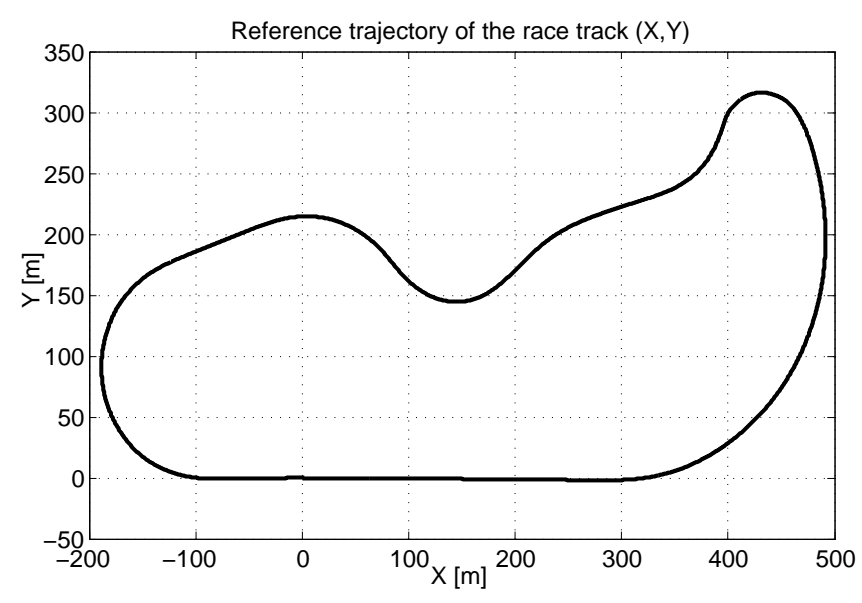

Figure 2: Reference trajectory of the race track

The main objective is achieved via a good choice of flat outputs. With such outputs, the flatness property of (1) is established, since, the nonlinear flat controller is designed. The scheme of Figure 1 shows the design steps and the interaction between them. The first step describes the computing of the reference flat outputs with real data and their derivatives. The used data, have been recorded with an instrumented vehicle during experiments realized on a race track with a professional driver. Then, the obtained trajectory is shown in Figure 2.

\section{Vehicle models and coupled dynamic analysis}

Two nonlinear vehicle models are used: the first one is a 3DoF NonLinear Two Wheels Model (3DoF-NLTWVM) which will be used to design a combined nonlinear control law. The second one is a $10 \mathrm{DoF}$ NonLinear Four Wheels Model (10DoF$N L F W V M$ ) which will be used in a complete vehicle simulator to test the proposed control law under various driving conditions. In the sequel, we present these models and the reasons for which the coupled nonlinear models are considered.

\subsection{DoF NonLinear Four Wheels Vehicle Simulation Model}

To perform some tests and evaluate the performance of combined controllers, a NonLinear Four Wheels Vehicle Model should be considered. This model is composed from: translational motions (longitudinal $x$, lateral $y$ and vertical $z$ ), rotational motions (roll $\phi$, pitch $\theta$ and yaw $\phi$ ) and wheels dynamics rotation motions (see Tables A.1 and A.2 for notations). All motions of the model are given in Appendix A.

\subsection{DoF Nonlinear Two Wheels Vehicle Control Model}

The 3DoF Nonlinear Two Wheels Vehicle Control Model (3DoF-NLTWVM) of Figure 3, provides a sufficient approximation of the longitudinal and lateral dynamics of the vehicle. It is used to design a combined controller and composed of the 


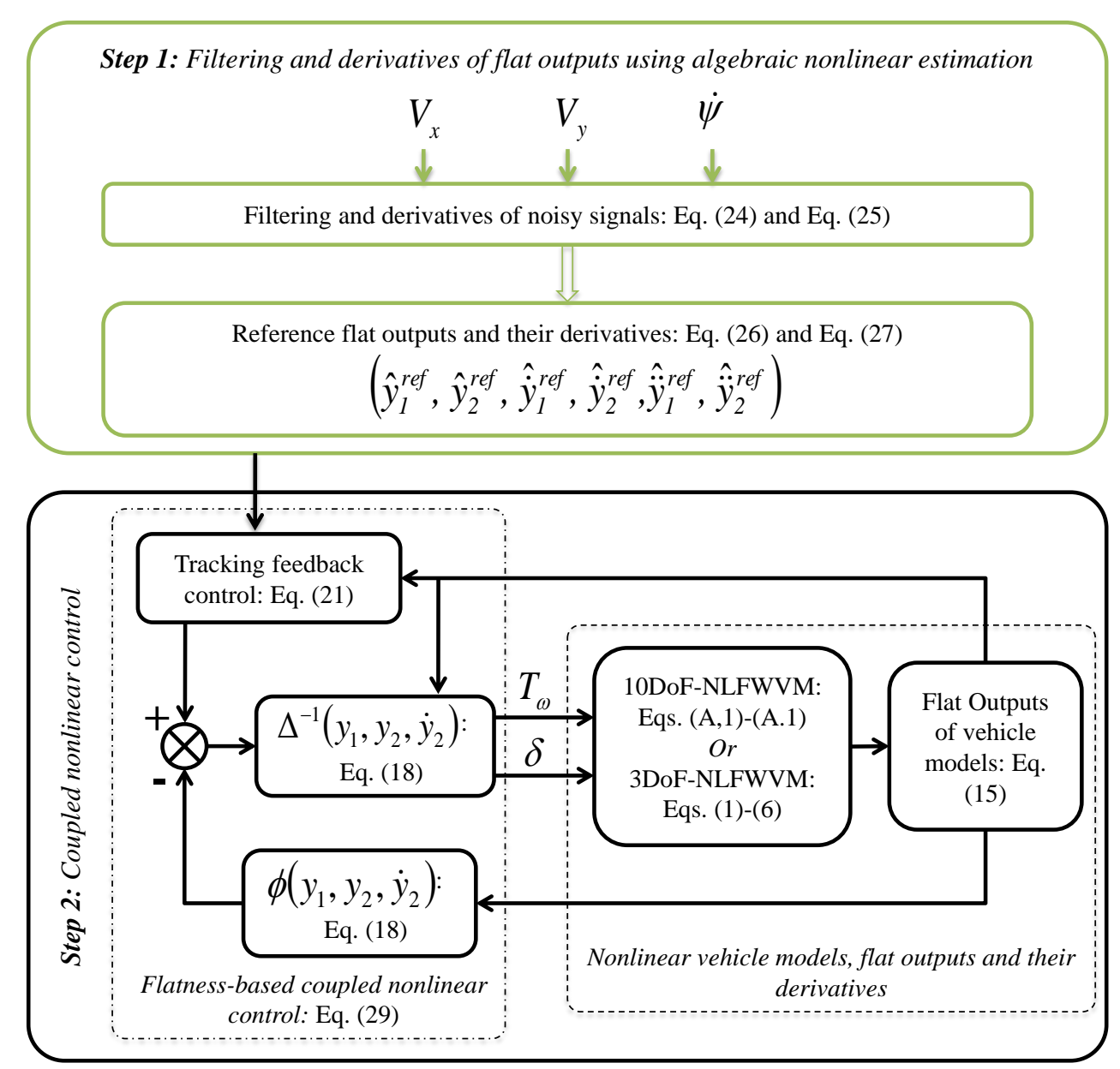

Figure 1: Interaction between the algebraic estimation and flatness-based coupled nonlinear control

longitudinal $V_{x}$, lateral $V_{y}$ and yaw $\dot{\psi}$ motions (see tables A.1 and A.2 for notations). Its equations are:

$$
\left\{\begin{array}{l}
m a_{x}=m\left(\dot{V}_{x}-\dot{\psi} V_{y}\right)=\left(F_{x 1}+F_{x 2}\right) \\
m a_{y}=m\left(\dot{V}_{y}+\dot{\psi} V_{x}\right)=\left(F_{y 1}+F_{y 2}\right) \\
I_{z} \ddot{\psi}=M_{z 1}+M_{z 2}
\end{array}\right.
$$

The forces and moments of Eq. (1) in the vehicle coordinates taking into account the kinetics coupling are:

$$
\left\{\begin{array}{l}
F_{x 1}=F_{x f} \cos (\delta)-F_{y f} \sin (\delta) \\
F_{x 2}=F_{x r} \\
F_{y 1}=F_{x f} \sin (\delta)+F_{y f} \cos (\delta) \\
F_{y 2}=F_{y r} \\
M_{z 1}=L_{1}\left(F_{y f} \cos (\delta)+F_{x f} \sin (\delta)\right) \\
M_{z 2}=-L_{2} F_{y r}
\end{array}\right.
$$

Considering small steering angles assumption, the forces and moments, in Eq. (2) become

$$
\left\{\begin{array}{l}
F_{x 1}=F_{x f}-F_{y f} \delta, F_{x 2}=F_{x r} \\
F_{y 1}=F_{x f} \delta+F_{y f}, F_{y 2}=F_{y r} \\
M_{z 1}=L_{1}\left(F_{y f}+F_{x f} \boldsymbol{\delta}\right), M_{z 2}=-L_{2} F_{y r}
\end{array}\right.
$$

In Eq. (1) the longitudinal forces are calculated using the dynamical model of the wheels. For the front wheel:

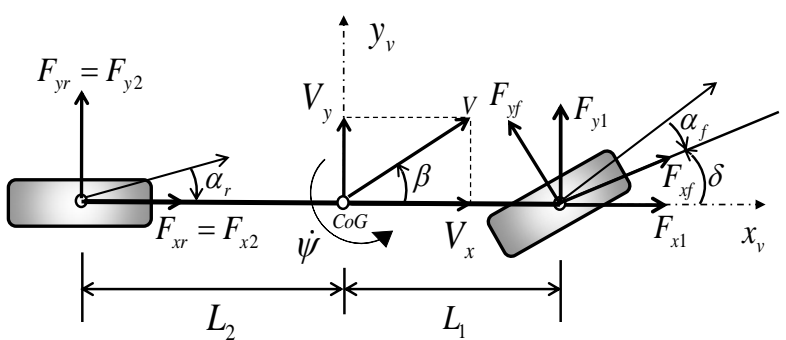

Figure 3: Nonlinear two wheeled vehicle model

$$
F_{x f}=(1 / R)\left(-I_{\omega} \dot{\omega}_{f}+T_{m}-T_{b f}\right)
$$

Considering that the vehicle is only propelled by the front wheel, the dynamical model of the rear wheel is as follows:

$$
F_{x r}=-(1 / R)\left(T_{b r}+I_{\omega} \dot{\omega}_{r}\right)
$$

The wheels rotations $\omega_{f}$ and $\omega_{r}$ are assumed to be measured through odometers. They are introduced as external inputs in the equations of the 3DoF-NLTWVM. For our simulations, we assume that the rear braking torque $T_{b r}$ can be expressed as proportional to the front braking torque $T_{b f}$, then, $T_{b r}=r T_{b f}$ 
where $0 \leq r \leq 1$ is a repartition braking coefficient between front and rear wheels. The wheels rotation accelerations will be estimated using the algebraic estimation and the measured rotation speeds which are available on the vehicle's CAN bus. Note that we have considered lateral tyre forces to be proportional to the sideslip angles of each axle. The front and rear forces $\left(F_{y f}=C_{f} \alpha_{f}, F_{y r}=C_{r} \alpha_{r}\right)$ are defined as follows:

$$
\left\{\begin{array}{l}
F_{y f}=C_{f}\left(\delta-\frac{V_{y}+\dot{\psi} L_{1}}{V_{x}}\right) \\
F_{y r}=-C_{r}\left(\frac{V_{y}-\dot{\psi} L_{2}}{V_{x}}\right)
\end{array}\right.
$$

where $C_{f}$ and $C_{r}$ are the cornering stiffness cofficients for the front and rear tyres respectively. The longitudinal speed is considered different from zero $\left(V_{x}>\varepsilon\right)$. Replacing Eqs. (3), (4), (5) and (6) in Eq. (1) yields:

$$
\left\{\begin{aligned}
m \dot{V}_{x}= & m \dot{\psi} V_{y}-\frac{I_{\omega}}{R}\left(\dot{\omega}_{r}+\dot{\omega}_{f}\right)+\frac{1}{R}\left(T_{m}-T_{b f}-T_{b r}\right) \\
& +C_{f}\left(\frac{V_{y}+L_{1} \dot{\psi}}{V_{x}}\right) \delta-C_{f} \delta^{2} \\
m \dot{V}_{y}= & -m \dot{\psi} V_{x}-C_{f}\left(\frac{V_{y}+L_{1} \dot{\psi}}{V_{x}}\right)-C_{r}\left(\frac{V_{y}-\dot{\psi} L_{2}}{V_{x}}\right) \\
& +(1 / R)\left(T_{m}-T_{b f}\right) \delta+\left(C_{f}-\frac{I_{\omega}}{R} \dot{\omega}_{f}\right) \delta \\
I_{z} \ddot{\psi}=\quad & -L_{1} C_{f}\left(\frac{V_{y}+L_{1} \dot{\psi}}{V_{x}}\right)+L_{2} C_{r}\left(\frac{V_{y}-L_{2} \dot{\psi}}{V_{x}}\right) \\
& +\left(L_{1} / R\right)\left(T_{m}-T_{b f}\right) \delta+L_{1}\left(T_{m}-\frac{I_{\omega}}{R} \dot{\omega}_{f}\right) \delta
\end{aligned}\right.
$$

The longitudinal movement is controlled via the driving/braking wheel torque $T_{\omega}=T_{m}-T_{b}$ with $T_{b}=T_{b f}+T_{b r}$, and the lateral movement via the steering angle $\delta$. Let us denote the two control variables:

$$
\left\{\begin{array}{l}
u_{1}=T_{\omega} \\
u_{2}=\delta
\end{array}\right.
$$

The model given by Eq. (7) may now be written as follows:

$$
\dot{x}=f(x, t)+g(x) u+g_{1} u_{1} u_{2}+g_{2} u_{2}^{2}
$$

where:

$$
\begin{aligned}
& f(x, t)=\left[\begin{array}{c}
\dot{\psi} V_{y}-\frac{I_{\omega}}{m R}\left(\dot{\omega}_{r}+\dot{\omega}_{f}\right) \\
-\dot{\psi} V_{x}+\frac{1}{m}\left(-C_{f}\left(\frac{V_{y}+L_{1} \dot{\psi}}{V_{x}}\right)-C_{r}\left(\frac{V_{y}-L_{2} \dot{\psi}}{V_{x}}\right)\right) \\
\frac{1}{I_{z}}\left(-L_{1} C_{f}\left(\frac{V_{y}+L_{1} \dot{\psi}}{V_{x}}\right)+L_{2} C_{r}\left(\frac{V_{y}-L_{2} \dot{\psi}}{V_{x}}\right)\right)
\end{array}\right], \\
& g(x, t)=\left[\begin{array}{cc}
\frac{1}{m R} & \frac{C_{f}}{m}\left(\frac{V_{y}+L_{1} \dot{\psi}}{V_{x}}\right) \\
0 & \left(C_{f} R-I_{\omega} \dot{\omega}_{f}\right) / m R \\
0 & \left(L_{1} C_{f} R-L_{1} I_{\omega} \dot{\omega}_{f}\right) / I_{z} R
\end{array}\right], g_{1}=\left[\begin{array}{c}
0 \\
\frac{1}{m R} \\
\frac{L_{1}}{I_{z} R}
\end{array}\right] \text {, } \\
& g_{2}=\left[\begin{array}{c}
\frac{-C_{f}}{m} \\
0 \\
0
\end{array}\right]^{T}, x=\left[\begin{array}{c}
V_{x} \\
V_{y} \\
\dot{\psi}
\end{array}\right]^{T}, u=\left[\begin{array}{l}
u_{1} \\
u_{2}
\end{array}\right]
\end{aligned}
$$

Remark 1. As mentioned previously, to ensure an efficient control and perform coupled driving maneuvers, a combined lateral/longitudinal controller is required. The design of such a controller requires coupled vehicle models. The vehicle models (A.1) and (1) satisfy these requirements, which include the following coupling effects:
- Kinematic coupling: We give a brief description of the kinematic relationship between the vehicle motions like steering and yaw motions. When the vehicle wheels are steered, the longitudinal and lateral forces are functions of the wheel forces and steering angle (see Eqs. (A.4) and (2)). The same reasoning is done for the lateral and the longitudinal displacements, which are also functions of the yaw angle, longitudinal and lateral speeds (see Eq. (A.2)).

- Load transfer coupling: The load transfer plays a crucial role in the stability analysis of the vehicle dynamics. This coupling is the consequence of two important points: the first one is related to the road geometry parameters like road bank angle, road slope angle and road curvature, the second one is due mainly to the vehicle dynamics like longitudinal and lateral accelerations, roll and suspension motions. These points change the weight distribution between the front, rear, right and left tyres. Such parameters and motions act strongly on the weight distribution between the vehicle's tyres. All these coupling effects are expressed through the tyre vertical forces model (A.5).

- Coupling of tyre behavior: The behavior of the vehicle models strongly depend on tyre-road forces. The coupled tyre models (A.3) represent only the relationship between the road and the vehicle and are required to ensure a realistic behavior of the vehicle. Such a model considers the coupling of longitudinal slip ratio, sideslip angle, vertical forces and camber angle.

\section{Flatness-based control}

Flatness-based control ((Fliess et al., 1995, 1999) and (Lévine, 2009; Sira-Ramírez \& Agrawal, 2004)) has already found numerous engineering applications. See, e.g., for coupled nonlinear vehicles (Fuchshumer et al., 2005; Menhour et al., 2011, 2012) and for underwater vehicles (Rathinam \& Murray, 1998). Flatness is demonstrated for a 3DoF nonlinear two wheels vehicle model of the form depicted in (14).

\subsection{Flatness property: A short summary}

Consider the system

$$
\dot{x}=f(x, u)
$$

where $x=\left(x, \cdots, x_{n}\right) \in \mathbb{R}^{n}$ and $u=\left(u, \cdots, u_{m}\right) \in \mathbb{R}^{m}$. It is said to be (differentially) flat (see (Fliess et al., 1995, 1999) and (Sira-Ramírez \& Agrawal, 2004; Lévine, 2009)) if, and only if:

- there exists a vector-valued function $h$ such that

$$
y=h\left(x, u, \dot{u}, \cdots, u^{(r)}\right)
$$

where $y=\left(y, \cdots, y_{m}\right) \in \mathbb{R}^{m}, r \in \mathbb{N}$; 
- the components of $x=\left(x, \cdots, x_{n}\right)$ and $u=\left(u, \cdots, u_{m}\right)$ may be expressed as

$$
\begin{aligned}
& x=A\left(y, \dot{y}, \cdots, y^{\left(r_{x}\right)}\right), \quad r_{x} \in \mathbb{N} \\
& u=B\left(y, \dot{y}, \cdots, y^{\left(r_{u}\right)}\right), r_{u} \in \mathbb{N}
\end{aligned}
$$

Remember that $y$ in Eq. (11) is called a flat output. It is well known that a flat system is equivalent to a linear one via an endogenous feedback (Fliess et al., 1995, 1999) and (Lévine, 2009; Sira-Ramírez \& Agrawal, 2004). ${ }^{1}$

\subsection{Flatness-based longitudinal and lateral control}

In order to reduce the complexity of the nonlinear model in Eq. (9), nonlinear terms such as $u_{1} u_{2}$ and $u_{2}^{2}$ are neglected. ${ }^{2}$ Despite these simplifications, coupled behaviors are kept as shown by the functions $f(x, t)$ and $g(x, t)$. Eq. (9) becomes:

$$
\dot{x}=f(x, t)+g(x, t) u
$$

\subsubsection{A proof of flatness}

Proof. We want to show that $y_{1}$ and $y_{2}$ given by

$$
\left\{\begin{array}{l}
y_{1}=V_{x} \\
y_{2}=L_{1} m V_{y}-I_{z} \dot{\psi}
\end{array}\right.
$$

define flat outputs for system (14). Some algebraic manipulations yield

$$
\begin{aligned}
x= & A\left(y_{1}, y_{2}, \dot{y}_{2}\right) \\
= & {\left[\begin{array}{c}
y_{1} \\
\frac{y_{2}}{L_{1} m}-\left(\frac{I_{z}}{L_{1} m}\right)\left(\frac{L_{1} m y_{1} \dot{y}_{2}+C_{r}\left(L_{1}+L_{2}\right) y_{2}}{C_{r}\left(L_{1}+L_{2}\right)\left(I_{z}-L_{2} L_{1} m\right)+\left(L_{1} m y_{1}\right)^{2}}\right) \\
-\left(\frac{L_{1} m y_{1} \dot{y}_{2}+C_{r}\left(L_{1}+L_{2}\right) y_{2}}{C_{r}\left(L_{1}+L_{2}\right)\left(I_{z}-L_{2} L_{1} m\right)+\left(L_{1} m y_{1}\right)^{2}}\right)
\end{array}\right] }
\end{aligned}
$$

and

$$
\left[\begin{array}{c}
\dot{y}_{1} \\
\ddot{y}_{2}
\end{array}\right]=\Delta\left(y_{1}, y_{2}, \dot{y}_{2}\right)\left(\begin{array}{c}
u_{1} \\
u_{2}
\end{array}\right)+\Phi\left(y_{1}, y_{2}, \dot{y}_{2}\right)
$$

Then

$$
\left[\begin{array}{l}
u_{1} \\
u_{2}
\end{array}\right]=\Delta^{-1}\left(y_{1}, y_{2}, \dot{y}_{2}\right)\left(\left[\begin{array}{l}
\dot{y}_{1} \\
\ddot{y}_{2}
\end{array}\right]-\Phi\left(y_{1}, y_{2}, \dot{y}_{2}\right)\right)
$$

where

\footnotetext{
${ }^{1}$ An endogenous feedback is a peculiar type of dynamic feedback.

${ }^{2}$ The results of Section 6 fully justify those approximations.
}

$$
\left\{\begin{aligned}
\Delta_{11}\left(y_{1}, y_{2}, \dot{y}_{2}\right)= & \frac{1}{m R} \\
\Delta_{12}\left(y_{1}, y_{2}, \dot{y}_{2}\right)= & \frac{C_{f}}{m}\left(\frac{V_{y}+L_{1} \dot{\psi}}{y_{1}}\right) \\
\Delta_{22}\left(y_{1}, y_{2}, \dot{y}_{2}\right)= & \left(\frac{L_{2} C_{r}\left(L_{1}+L_{2}\right)-L_{1} m y_{1}^{2}}{y_{1}}\right)\left(\frac{L_{1} C_{f} R-L_{1} I_{\omega} \dot{\omega}_{f}}{I_{z} R}\right) \\
& +\left(\frac{\left(C_{r}\left(L_{1}+L_{2}\right)\left(V_{y}-L_{2} \dot{\psi}\right)-L_{1} m \dot{\psi} y_{1}^{2}\right)}{y_{1}^{2}}\right) \times \\
& \left(\frac{C_{f}\left(V_{y}+L_{1} \dot{\psi}\right)}{m y_{1}}\right)-\left(\frac{C_{r}\left(L_{1}+L_{2}\right)}{y_{1}} \frac{R C_{f}-I_{\omega} \dot{\omega}_{f}}{m R}\right) \\
\Delta_{21}\left(y_{1}, y_{2}, \dot{y}_{2}\right)= & \left(\frac{C_{r}\left(L_{1}+L_{2}\right)\left(V_{y}-L_{2} \dot{\psi}\right)-L_{1} m \dot{\psi} y_{1}^{2}}{m R y_{1}^{2}}\right)
\end{aligned}\right.
$$

and

$$
\left\{\begin{aligned}
\Phi_{1}\left(y_{1}, y_{2}, \dot{y}_{2}\right)= & \dot{\psi} V_{y}-\frac{I_{\omega}}{m R}\left(\dot{\omega}_{r}+\dot{\omega}_{f}\right) \\
\Phi_{2}\left(y_{1}, y_{2}, \dot{y}_{2}\right)= & -L_{1} m y_{1} f_{3}(x, t)-\frac{C_{r}\left(L_{1}+L_{2}\right)}{y_{1}} f_{2}(x, t) \\
& +\frac{C_{r}\left(L_{1}+L_{2}\right)\left(V_{y}-L_{2} \dot{\psi}\right)-L_{1} m \dot{\psi} y_{1}^{2}}{y_{1}^{2}} f_{1}(x, t) \\
& +\frac{L_{2} C_{r}\left(L_{1}+L_{2}\right)}{y_{1}} f_{3}(x, t)
\end{aligned}\right.
$$

The flatness property holds therefore if the matrix $\Delta\left(y_{1}, y_{2}, \dot{y}_{2}\right)$ is invertible. It reads

$$
\begin{gathered}
\operatorname{det}\left(\Delta\left(y_{1}, y_{2}, \dot{y}_{2}\right)\right)=\Delta_{11} \Delta_{22}-\Delta_{21} \Delta_{12} \\
=\frac{\left(I_{\omega} \dot{\omega}_{f}-C_{f} R\right)\left(L_{1}^{2} y_{1}^{2} m^{2}-C_{r}\left(L_{1}+L_{2}\right) L_{2} L_{1} m+C_{r} I_{z} L\right)}{I_{z} R^{2} y_{1} m^{2}} \neq 0
\end{gathered}
$$

This determinant, which depends only on the longitudinal speed $y_{1}=V_{x}$, is indeed nonzero:

- The wheel rotation acceleration is less than $R C_{f} / I_{\omega}$ : $R C_{f} / I_{\omega}$ is around $10^{4}$, then $I_{\omega} \dot{\omega}_{f}-C_{f} R \neq 0$.

- Notice that $I_{z}>L_{1} m$, then: $C_{r}\left(L_{2}+L_{1}\right)\left(I_{z}-L_{1} m\right)+$ $L_{1}^{2} m^{2} y_{1}^{2} \neq 0$.

Thus

$$
\left\{\begin{aligned}
u & =B\left(y_{1}, \dot{y}_{1}, y_{2}, \dot{y}_{2}, \ddot{y}_{2}\right) \\
& =\Delta^{-1}\left(y_{1}, y_{2}, \dot{y}_{2}\right)\left(\left[\begin{array}{l}
\dot{y}_{1} \\
\ddot{y}_{2}
\end{array}\right]-\Phi\left(y_{1}, y_{2}, \dot{y}_{2}\right)\right)
\end{aligned}\right.
$$

with $r_{x}=1$ and $r_{u}=2$ and

$$
\left[\begin{array}{l}
\dot{y}_{1} \\
\ddot{y}_{2}
\end{array}\right]=\left[\begin{array}{c}
\dot{y}_{1}^{r e f}+K_{1}^{1} e_{y_{1}}+K_{1}^{2} \int e_{y_{1}} d t \\
\ddot{y}_{2}^{r e f}+K_{2}^{1} e_{y_{2}}+K_{2}^{2} \int e_{y_{2}} d t+K_{2}^{3} \dot{e}_{y_{2}}
\end{array}\right]
$$

where, $e_{y_{1}}=y_{1}^{r e f}-y_{1}=V_{x}^{r e f}-V_{x}$ and $e_{y_{2}}=y_{2}^{r e f}-y_{2}$. The gain tuning $K_{1}^{1}, K_{1}^{2}, K_{2}^{1}, K_{2}^{2}$ and $K_{2}^{3}$ is then straightforward thanks to the equivalent with linear systems (see Section 4.1). 


\section{Algebraic estimation}

Measured variables and their derivatives are needed in the control law (21) which is constructed via derivatives of reference outputs. See (Villagra et al., 2009, 2011; Abouaïssa et al., 2012) for previous successful applications to intelligent transportation systems.

\subsection{Denoising and numerical derivation: a short summary}

Start, for simplicity's sake, with a time signal corresponding to the first degree polynomial time function $p_{1}(t)=a_{0}+a_{1} t$, $t \geq 0, a_{0}, a_{1} \in \mathbb{R}$. Rewrite, thanks to classic operational calculus (see, e.g., (Yosida, 1984)) $p_{1}$ as $P_{1}=\frac{a_{0}}{s}+\frac{a_{1}}{s^{2}}$. Multiply both sides by $s^{2}$ :

$$
s^{2} P_{1}=a_{0} s+a_{1}
$$

Take the derivative of both sides with respect to $s$, which corresponds in the time domain to the multiplication by $-t$ :

$$
s^{2} \frac{d P_{1}}{d s}+2 s P_{1}=a_{0}
$$

The coefficients $a_{0}, a_{1}$ are obtained via the triangular system of Eqs. (22)-(23). We get rid of the time derivatives, i.e., of $s P_{1}$, $s^{2} P_{1}$, and $s^{2} \frac{d P_{1}}{d s}$, by multiplying both sides of Eqs. (22)-(23) by $s^{-n}, n \geq 2$. The corresponding iterated time integrals are low pass filters which attenuate the corrupting noises, viewed as highly fluctuating phenomena (see (Fliess, 2006; Fliess et al., 2008)). A quite short time window is sufficient for obtaining accurate values of $a_{0}, a_{1}$. The extension to polynomial functions of higher degree is straightforward. For derivatives estimates up to some finite order of a given smooth function $f:[0,+\infty) \rightarrow \mathbb{R}$, take a suitable truncated Taylor expansion around a given time instant $t_{0}$, and apply the previous computations. Resetting and using sliding time windows allow to estimate derivatives of various orders at any sampled time instant. ${ }^{3}$ The following formulae may be used in practice and yield straightforward discrete linear filters:

- Denoising:

$$
\hat{y}(t)=\frac{2 !}{T^{2}} \int_{t-T}^{t}(2 T-3 \tau) y(\tau) d \tau
$$

- Numerical differentiation of a noisy signal:

$$
\hat{\dot{y}}(t)=-\frac{3 !}{T^{3}} \int_{t-T}^{t}(T-2 \tau) y(\tau) d \tau
$$

Note that the sliding time window $[t-T, t]$ may be quite short.

\footnotetext{
${ }^{3}$ See (Fliess et al., 2008; Mboup et al., 2009) for more details.
}

\subsection{Application}

- The estimated derivatives $\hat{\dot{V}}_{x}^{r e f}, \hat{\dot{V}}_{y}^{r e f}, \hat{\hat{\psi}}^{r e f}, \hat{\dot{\omega}}_{f}$ and $\hat{\hat{\omega}}_{r}$ are performed as follows:

$$
\left[\begin{array}{c}
\hat{\dot{V}}_{x}^{r e f} \\
\hat{\dot{V}}_{y}^{r e f} \\
\hat{\tilde{\psi}}^{r e f} \\
\hat{\dot{\omega}}_{f} \\
\hat{\hat{\omega}}_{r}
\end{array}\right]=-\frac{3 !}{T^{3}} \int_{t-T}^{t}(2 T(t-\tau)-T)\left[\begin{array}{c}
V_{x}^{r e f} \\
V_{y}^{r e f} \\
\dot{\psi}^{r e f} \\
\omega_{f} \\
\omega_{r}
\end{array}\right] d \tau
$$

- The filtering of $\hat{\dot{V}}_{x}^{r e f}, \hat{\dot{V}}_{y}^{r e f}$ and $\hat{\dot{\psi}}^{r e f}$ is performed as follows:

$$
\left[\begin{array}{c}
\hat{V}_{x}^{r e f} \\
\hat{V}_{y}^{r e f} \\
\hat{\dot{\psi}}^{r e f}
\end{array}\right]=\frac{2 !}{T^{2}} \int_{t-T}^{t}(3(t-\tau)-T) y(\tau)\left[\begin{array}{c}
V_{x}^{r e f} \\
V_{y}^{r e f} \\
\dot{\psi}^{r e f}
\end{array}\right] d \tau
$$

Then, the flat outputs references are computed using Eqs. (26) and (27) as follows:

$$
\left\{\begin{array}{l}
\hat{y}_{1}^{r e f}=\hat{V}_{x}^{r e f} \\
\hat{y}_{1}^{r e f}=\hat{\dot{V}}_{x}^{r e f} \\
\hat{y}_{2}^{r e f}=L_{1} m \hat{V}_{y}^{r e f}-I_{z} \hat{\dot{\psi}}^{r e f} \\
\hat{y}_{2}^{r e f}=L_{1} m \hat{\dot{V}}_{y}^{r e f}-I_{z} \hat{\ddot{\psi}}^{r e f} \\
\hat{y}_{2}^{r e f}=L_{1} m \hat{\ddot{V}}_{y}^{r e f}-I_{z} \hat{\ddot{\psi}}^{r e f}
\end{array}\right.
$$

The tracking errors are:

$$
\left\{\begin{array}{l}
\hat{e}_{y_{1}}=\hat{y}_{1}^{r e f}-y_{1} \\
\hat{e}_{y_{2}}=\hat{y}_{2}^{r e f}-y_{2} \\
\hat{\dot{e}}_{y_{2}}=\hat{y}_{2}^{r e f}-\dot{y}_{2}
\end{array}\right.
$$

The equation of the coupled nonlinear control obtained from Eqs. (20), (21) and (28) reads:

$$
\begin{gathered}
u=\left[\begin{array}{c}
T_{\omega} \\
\delta
\end{array}\right]=-\Delta^{-1}\left(y_{1}, y_{2}, \dot{y}_{2}\right) \Phi\left(y_{1}, y_{2}, \dot{y}_{2}\right) \\
+\Delta^{-1}\left(y_{1}, y_{2}, \dot{y}_{2}\right) \times\left[\begin{array}{c}
\hat{y}_{1}^{r e f}+K_{1}^{1} \hat{e}_{y_{1}}+K_{1}^{2} \int \hat{e}_{y_{1}} d t \\
\hat{y}_{2}^{r e f}+K_{2}^{1} \hat{e}_{y_{2}}+K_{2}^{2} \int \hat{e}_{y_{2}} d t+K_{2}^{3} \hat{\dot{e}}_{y_{2}}
\end{array}\right]
\end{gathered}
$$

\section{Simulation tests: comparison with experimental tests}

Several experiments in presence of coupled driving/braking and steering maneuvers have been realized with an instrumented car. All trials are used to compute reference flat outputs and to deduce the blue curve of the race track depicted in Figure 11. For each trial, several dynamical parameters have been recorded at frequency $200 \mathrm{~Hz}$; among them: longitudinal and lateral speeds, lateral and longitudinal accelerations, yaw and roll rates, wheel rotation speeds, longitudinal, lateral and vertical forces on four wheels, moments on four wheels, steering angle, etc. For simulations tests, two vehicle models are used: the first one is a NonLinear Two Wheels Vehicle Model 


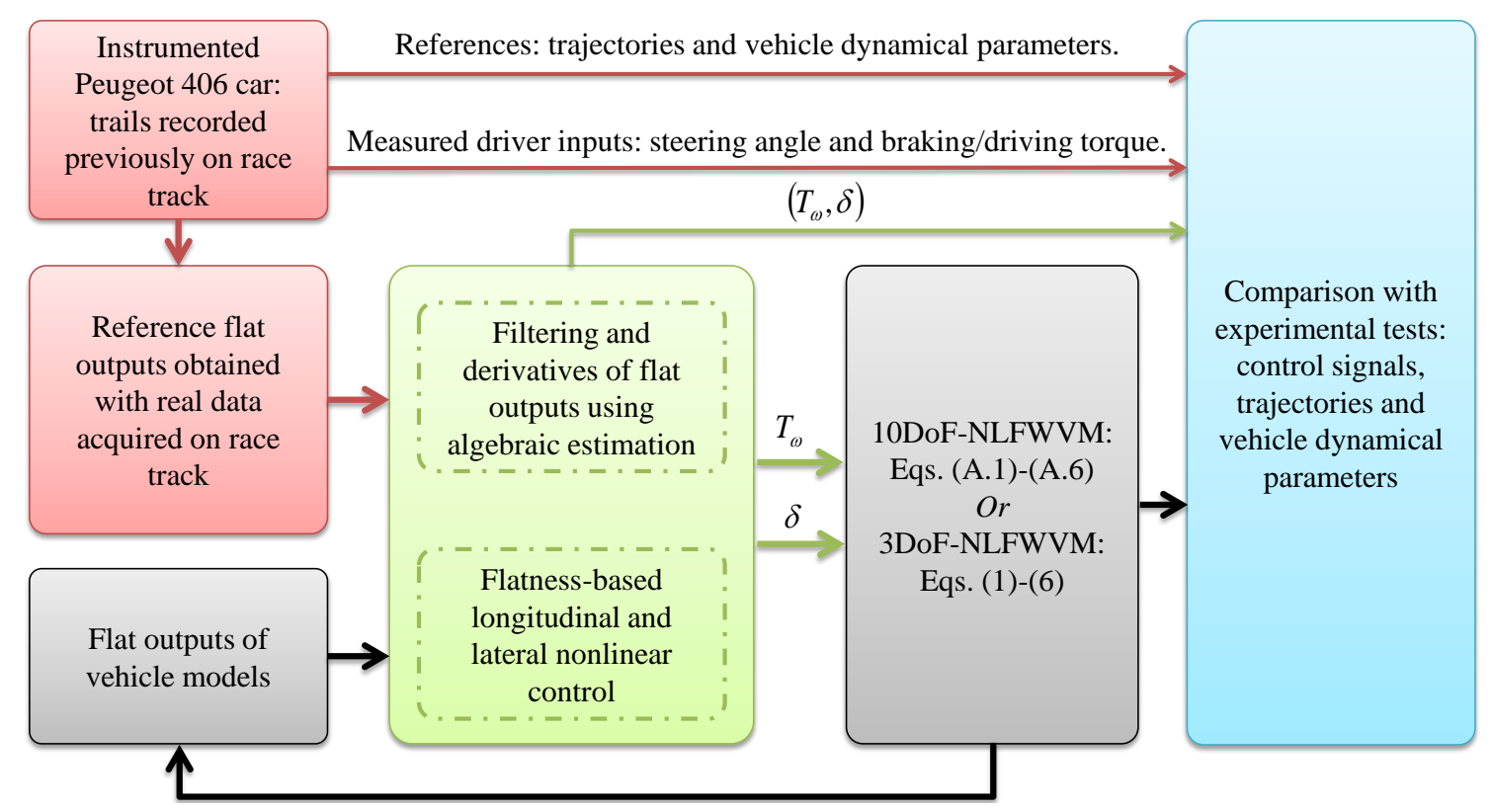

Figure 4: Validation diagram bloc: interaction between the algebraic estimation, vehicle models and flat nonlinear control

(1) (3DoF-NLTWVM), while the second is a full NonLinear Four Wheels Vehicle Model (A.1) (10DoF-NLFWVM).

Real data have been used firstly to generate the reference flat outputs, and secondly to compare them with the obtained results in closed-loop as shown in the validation scheme of Figure 4. More precisely, the blue curves of Figures 5-11 summarize the main measurements used for our validation. All measurements are recorded previously during a test conducted on a race track and employed for our simulations as reference signals. For all experiments, the professional driver has performed coupled maneuvers under high dynamical loads as highlighted by the blue curves of Figures 5-7. Moreover, we can observe that the coupled maneuvers like the steering control maneuver combined with accelerating action, and steering control maneuver combined with sudden and sharp braking action are performed.

Figures 5, 6 and 7 show that the obtained simulation results are close to the measurements such as yaw rate, longitudinal speed, longitudinal and lateral accelerations. Note also that the steering angle and braking/traction wheel torque provided by the combined control law are similar to the measured ones. These observations are valid for two vehicle models (3DoF or $10 \mathrm{DoF}$ ) and for the coupled maneuvers as illustrated in Figure 5 between the positions from $600 \mathrm{~m}$ to $750 \mathrm{~m}$ and from $1000 \mathrm{~m}$ to $1080 \mathrm{~m}$.

As mentioned previously, combined steering and braking maneuvers are simultaneously performed in the most dangerous curves of race track as depicted in Figures 8 and 11. The controller effectiveness in terms of tracking flat outputs errors are also depicted in Figures 9 and 10. Let us emphasize that the tracking errors are small and therefore the closed-loop behavior is quite satisfactory. Moreover, the tracking trajectory performance even under high dynamical loads with dangerous curves (lateral acceleration $-5 \mathrm{~m} / \mathrm{s}^{2} \leq a_{y} \leq 5 \mathrm{~m} / \mathrm{s}^{2}$ ).

Through the simulation results, we can observe the ability

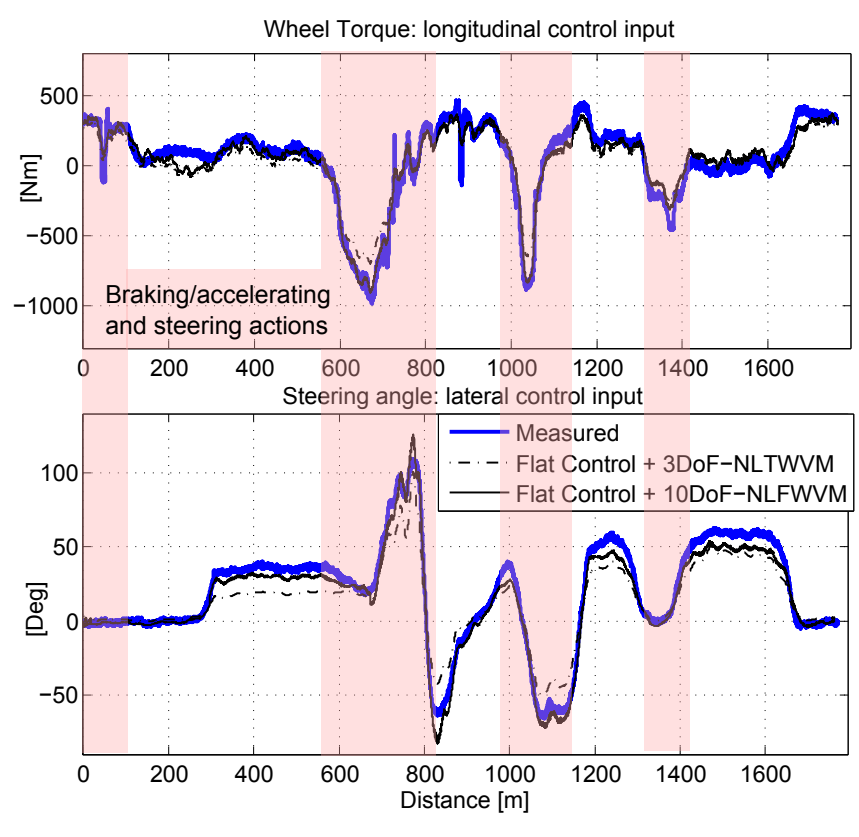

Figure 5: Control inputs: driving/braking torque control and steering angle

and the efficiency of the control law to produce an adequate behavior. Moreover, it is obvious that the behaviors of the controlled models are close to the real vehicle behavior. This observation is verified especially when the $10 \mathrm{DoF}$ vehicle model is coupled with the nonlinear flat controller. Indeed, as shown in Figure 8, the curvature of the controlled two wheels model is slightly different from the reference road curvature. In contrast, the performance in terms of the tracking trajectory is still satisfactory as shown in Figure 11 and for any given model.

The performance of the proposed controller for operating under extreme and coupled behaviors is also highlighted through 


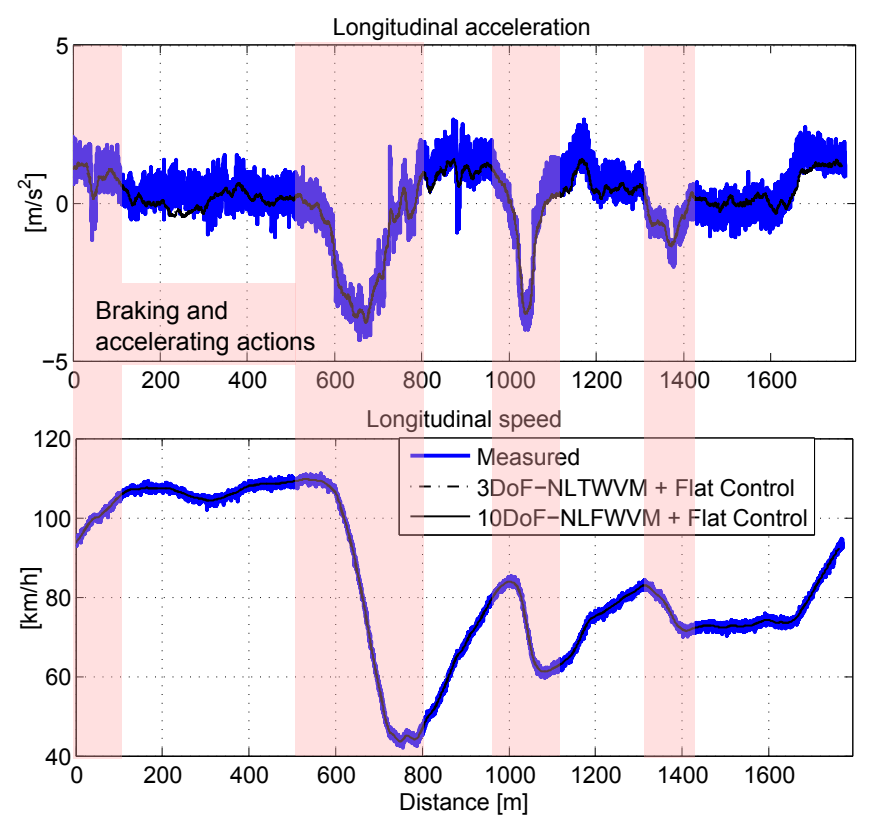

Figure 6: Longitudinal behavior of the controlled vehicle models and the actual one: longitudinal acceleration and longitudinal speed
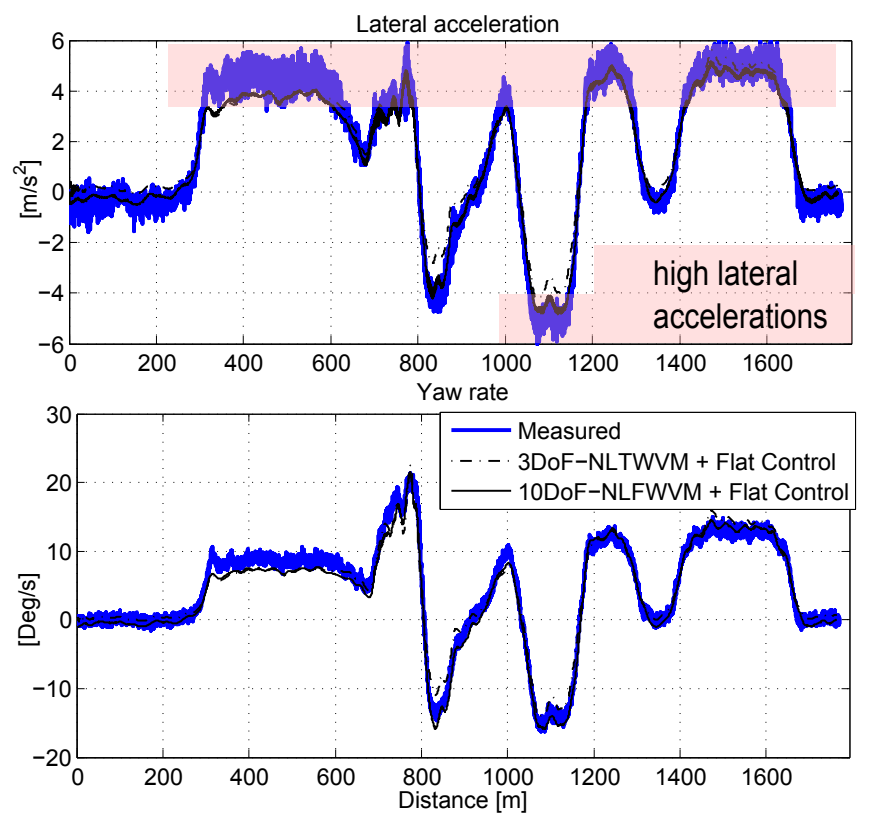

Figure 7: Lateral behavior of the controlled vehicle models and the actual one: lateral acceleration and yaw rate

the obtained results. On the other hand, the controller is able to operate with high values of lateral acceleration $\left(-5 \mathrm{~m} / \mathrm{s}^{2} \leq a_{y} \leq\right.$ $5 \mathrm{~m} / \mathrm{s}^{2}$ ) and longitudinal acceleration $\left(-5 \mathrm{~m} / \mathrm{s}^{2} \leq a_{x} \leq 2 \mathrm{~m} / \mathrm{s}^{2}\right)$, even in the presence of curved trajectories with a small radius of curvature $(20 m<R<35 \mathrm{~m})$. It should be pointed out that the emergency situations, such as collisions and obstacle avoidance, lane-change maneuvers, can easily cause critical driving situations. For this reason, the performance of the control law are tested under high dynamics loads and coupled maneuvers.

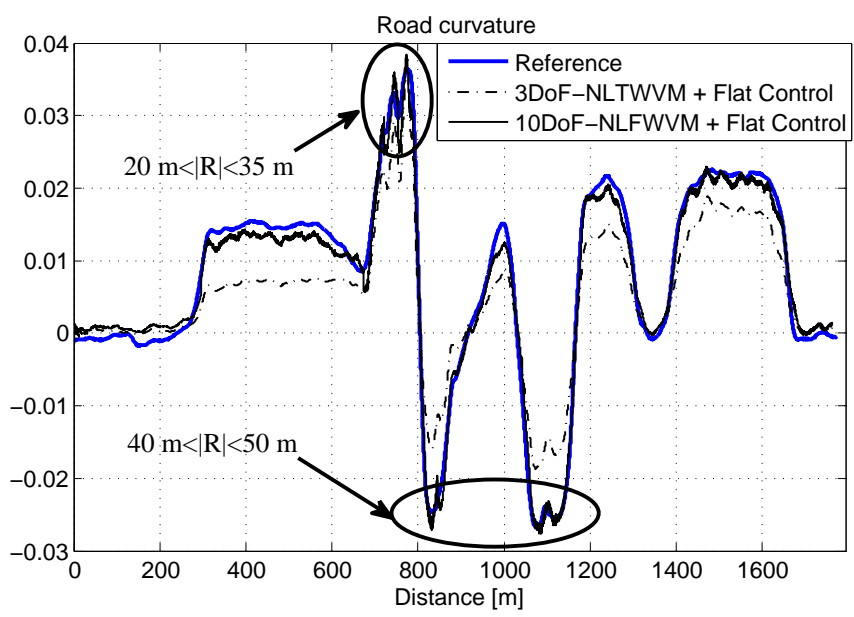

Figure 8: Curvatures: reference and controlled vehicle model curvatures

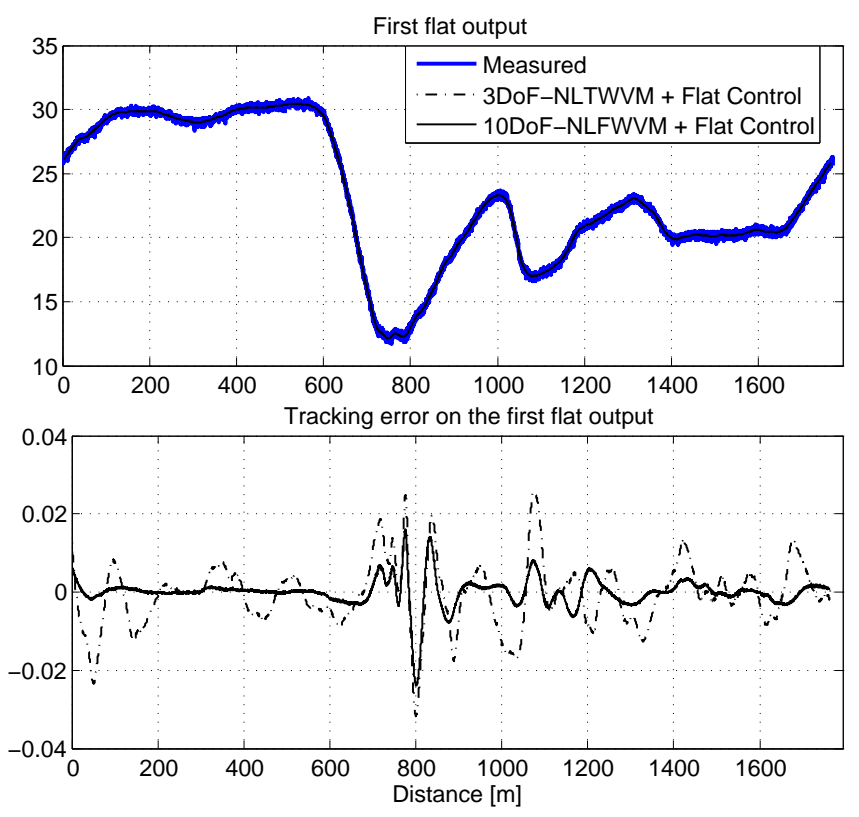

Figure 9: Tracking errors on the first output

Remark 2. Let us emphasize that our results show that the performance of the control law is not affected by the model simplifications: neglected nonlinear terms $u_{1} u_{2}$ and $u_{2}^{2}$ as shown by Figures 12, 13 and 14. It can be seen that the magnitude of these second order terms $u_{1} u_{2}$ and $u_{2}^{2}$ is small: the maximum value is less than 0.8 for $u_{1} u_{2}$ (Figure 12) and less than $210^{-3}$ for $u_{2}^{2}$ (Figure 13).

Moreover, the flatness-based control still works in spite of parameter uncertainties as shown by Figure 15 where the coefficients $C_{f}$ and $C_{r}$ are $30 \%$ reduced. Similar robustness considerations apply to the time-delay problem. Let us point out that for these tests, 20 samples delay have been applied. 

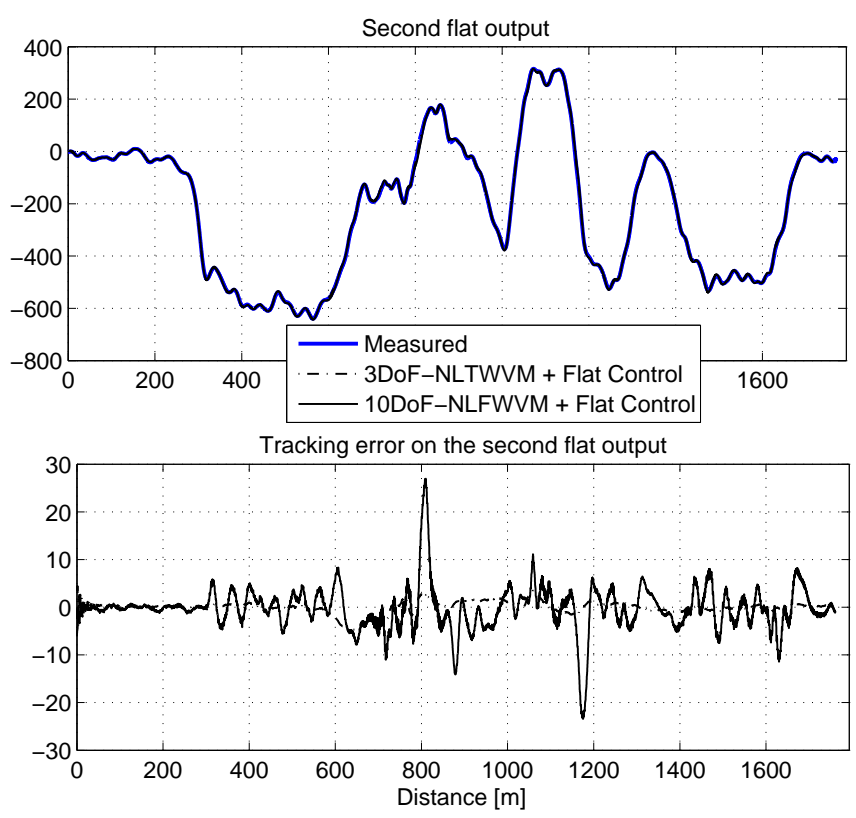

Figure 10: Tracking error on the second output

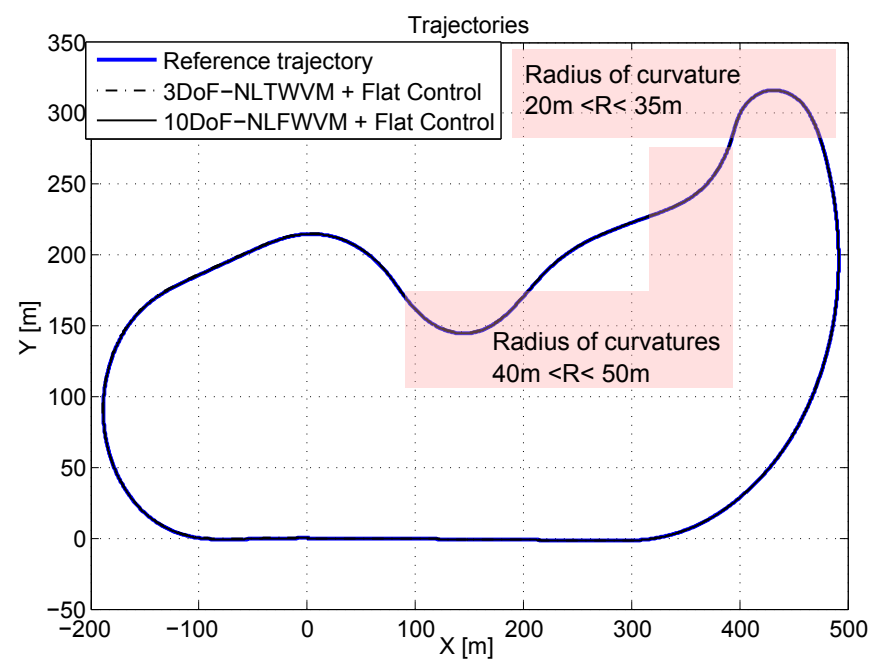

Figure 11: Trajectories: reference and controlled vehicle model

\section{Conclusions}

The proposed controller represents a promising solution for simultaneous control of longitudinal and lateral vehicle movements. To ensure the obtained results, a knowledge of nominal vehicle model is required. But, this knowledge is not guaranteed in the presence of fast dynamics like those induced by sudden changes of the road adherence and braking maneuvers leading to time-varying cornering stiffness coefficients. For this purpose, the recent work (Menhour et al., 2013) shows that, thanks to the new model-free control design (Fliess \& Join, 2013), ${ }^{4}$ some complex parameter identification might be avoided. It indicates possible simplifications for future works.

\footnotetext{
${ }^{4}$ See the references in (Fliess \& Join, 2013) for a numerous list of successful applications in most diverse domains.
}

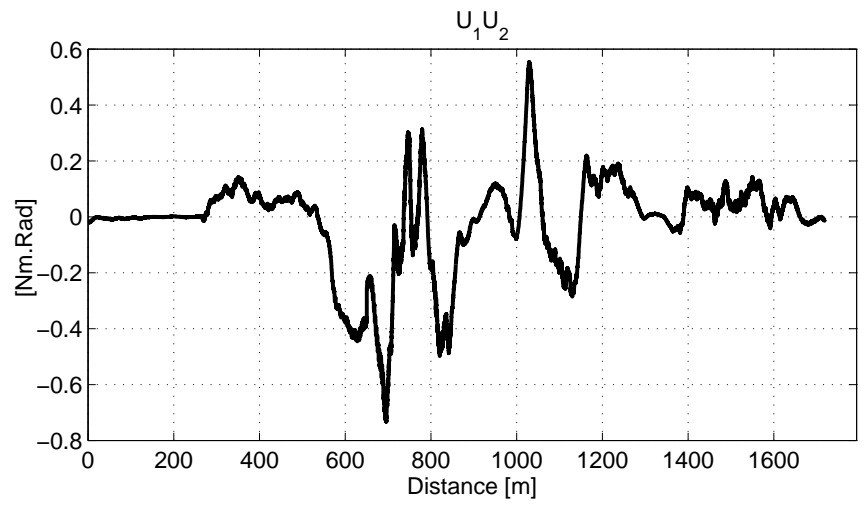

Figure 12: Magnitude of neglected nonlinear term $u_{1} u_{2}$

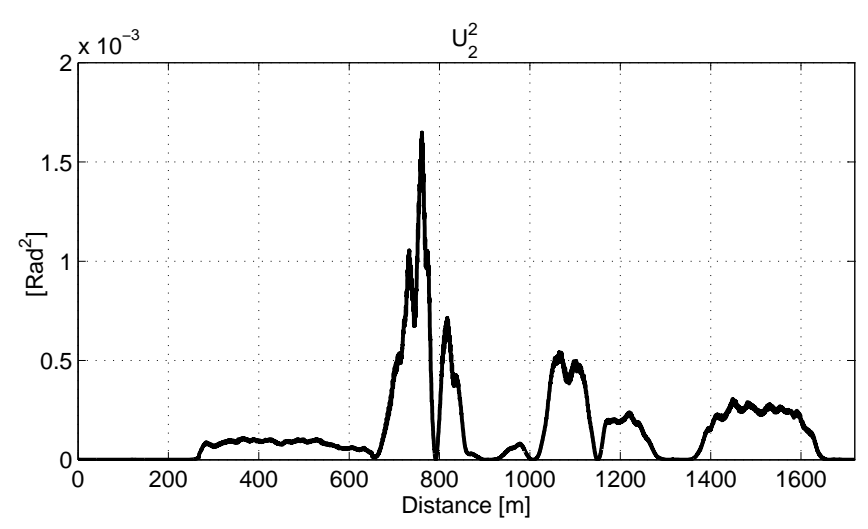

Figure 13: Magnitude of neglected nonlinear term $u_{2}^{2}$

\section{References}

Abouaïssa H., Fliess M., Iordanova V., Join, C., 2012. Freeway ramp metering control made easy and efficient, $13^{\text {th }}$ IFAC Symp. Control Transportation Systems, Sofia. Preprint available at

http://hal.archives-ouvertes.fr/hal-00711847/en/

Ackermann, J., Guldner, J., Sienel, W., Steinhauser, R., Utkin, V.I., 1995. Linear and nonlinear controller design for robust automatic steering, IEEE Trans. Control Syst. Techno., 3, 112-143.

d'Andréa-Novel, B., Ellouze, M., 2001. Tracking with stability for a vehicle braking in a corner, IEEE Conf. Decision Control, Orlando.

Cerone, V., Milanese, M., Regruto, D., 2009. Combined automatic lanekeeping and driver's steering through a 2-DOF control strategy, IEEE Trans. Control Syst. Techno., 17, 135-142.

Chou, H., d'Andréa-Novel, B., 2005. Global vehicle control using differential braking torques and active suspension forces, Vehicle Syst. Dynamics, 43, 261-284.

Fernandez-Llorca, D., Milanes, V., Parra Alonso, I., Gavilan, M., Garcia Daza, I., Perez J., Sotelo, M.A., 2011. Autonomous Pedestrian Collision Avoidance Using a Fuzzy Steering Controller, IEEE Trans. Intelligent Transport. Systems, 12, 390-401.

Fliess, M., 2006. Analyse non standard du bruit, C.R. Acad. Sci. Paris, I-342, 797-802.

Fliess, M., Join, C., 2013. Model-free control, Int. J. Control, DOI: 10.1080/00207179.2013.810345. Preprint available at http://hal.archives-ouvertes.fr/hal-00828135/en/

Fliess, M., Join, C., Sira-Ramírez, H., 2008. Non-linear estimation is easy, Int. J. Model. Identif. Control, 4, 12-27. Preprint available at newline http://hal.archives-ouvertes.fr/hal-00581109/en/

Fliess, M., Lévine, J., Martin, P., Rouchon, P., 1995. Flatness and defect of nonlinear systems: introductory theory and examples, Int. J. Control, 61, 1327-1361. 

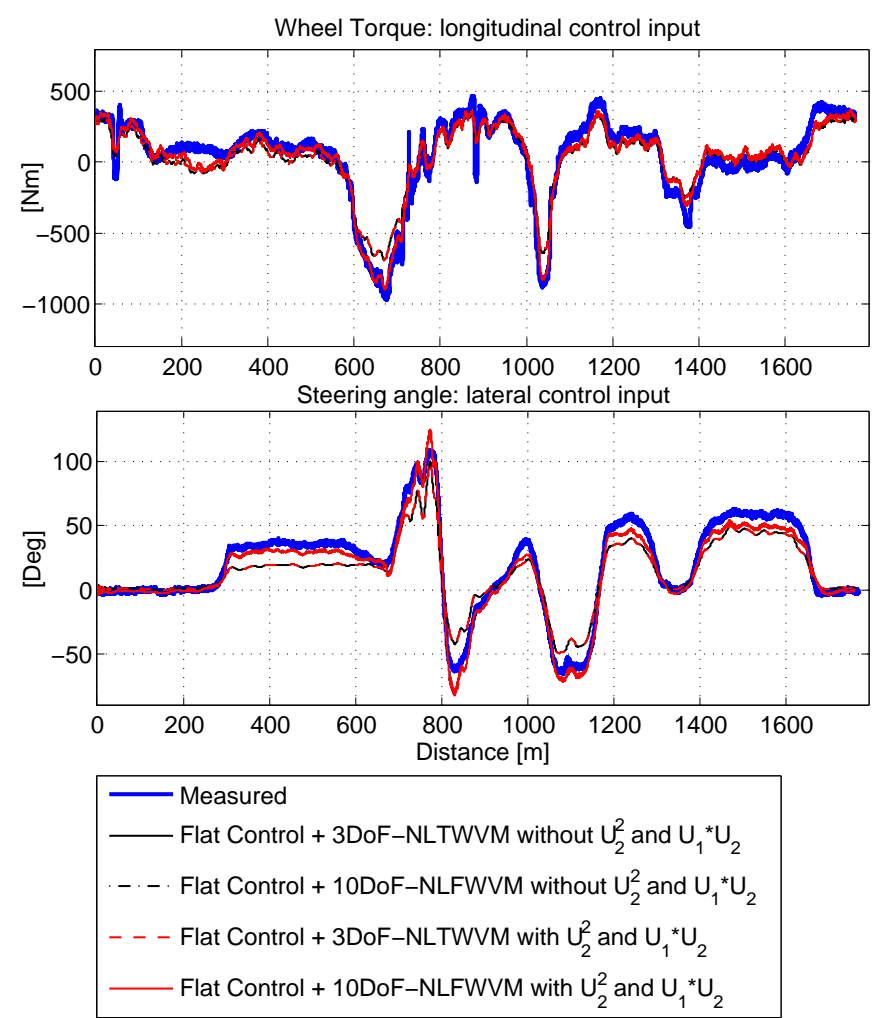

Figure 14: Simulations with and without nonlinear terms $u_{1} u_{2}$ and $u_{2}^{2}$
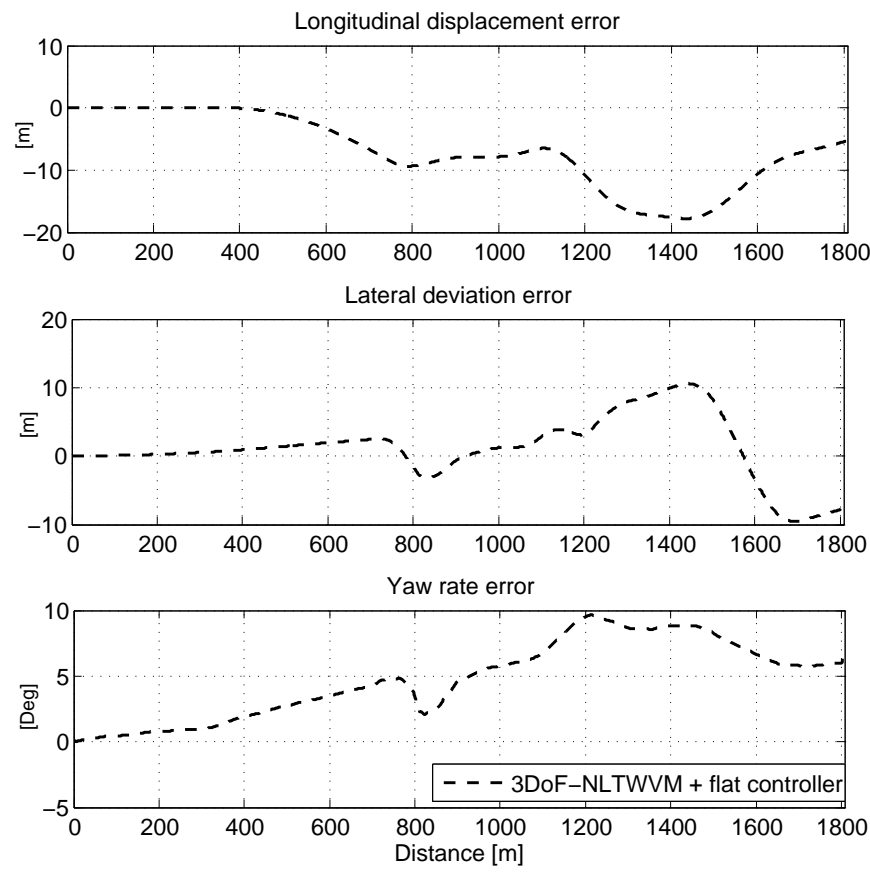

Figure 15: Tracking error performance with $30 \%$ reduced $C_{f}$ and $C_{r}$

Fliess, M., Lévine, J., Martin, P., Rouchon, P., 1999. A Lie-Bäcklund approach to equivalence and flatness of nonlinear systems, IEEE Transactions on Automatic Control, 44, 922-937.

Fuchshumer, S., Schlacher, K., Rittenschober, T., 2005. Nonlinear vehicle dynamics control - A flatness based approach, $44^{\text {th }}$ IEEE Conf. Decision Con- trol \& Europ. Control Conf., Sevilla.

Guldner, J., Sienel, W., Tan, H.S., Ackermann, J., Patwardhan, S., Bunte, T., 1999. Robust automatic steering control for look-down reference systems with front and rear sensors, IEEE Trans. Control Syst. Techno., 7, 2-11.

Hatipoglu, C., Özgüner, Ü., Redmill, K.A., 2003. Automated lane change controller design, IEEE Trans. Intelligent Transport. Syst., 4, 13-22.

Khodayari, A., Ghaffari, A., Ameli, S., Flahatgar, J., 2010. A historical review on lateral and longitudinal control of autonomous vehicle motions, IEEE Int. Conf. Mechanical Electrical Techno., Singapore.

Kiencke, N., Nielsen, L., 2004. Automotive Control Systems: For Engine, Driveline and Vehicle, Springer.

Lévine, J., 2009. Analysis and Control of Nonlinear Systems: A Flatness-based Approach, Springer.

Mammar S., Netto, M., 2004. Integrated longitudinal and lateral control for vehicle low speed automation, Proc. IEEE ICCA, Taiwan.

Marino, R., Cinili, F., 2009. Input-output decoupling control by measurement feedback in four wheel-steering-vehicles, IEEE Trans. Control Syst. Techno., 17, 1163-1172.

Martinez, J., Canudas-de-Wit, C., 2007. A safe longitudinal control for adaptive cruise control and stop-and-go scenarios, IEEE Trans. Control Syst. Techno., 15, 246-258.

Mboup, M., Join, C., Fliess, M., 2009. Numerical differentiation with annihilators in noisy environment, Numer. Algorithms, 50, 439-467.

Menhour, L., d'Andréa-Novel, B., Boussard, C., Fliess, M., Mounier, H., 2011. Algebraic nonlinear estimation and flatness-based lateral/longitudinal control for automotive vehicles, $14^{\text {th }}$ Int. IEEE Conf. Intelligent Transport. Syst., Washington. Preprint available at http://hal.archives-ouvertes.fr/hal-00611950/en/

Menhour, L., d'Andréa-Novel, B., Fliess, M., Mounier, H., 2013. Multivariable decoupled longitudinal and lateral vehicle control: A model-free design, $52^{\text {th }}$ IEEE Decision and Control, Florence. Preprint available at http://hal.archives-ouvertes.fr/hal-00859444/en/

Menhour, L., d'Andréa-Novel, B., Fliess, M., Mounier, H., 2012. Commande couplée longitudinale/latérale de véhicules par platitude et estimation algébrique, 7ème Conférence Internationale Francophone d'Automatique, Grenoble. Preprint available at http://hal.archives-ouvertes.fr/hal-00686653/en/

Menhour, L., Lechner, D., Charara, A., 2011c. Two degrees of freedom PID multi-controllers to design a mathematical driver model: Experimental validation and robustness tests, Vehicle Syst. Dynamics, 49, 595-624.

Nobe, S.A., Wang, F-Y., 2001. An overview of recent developments in automated lateral and longitudinal vehicle controls, IEEE Int. Conf. Syst. Man Cyber., Nashville.

Nouvelière L., Mammar, S., 2007. Experimental vehicle longitudinal control using a second order sliding modes technique, Control Engin. Practice, 15, 943-954.

H. B. Pacejka, 2006. Tyre and Vehicle Dynamics ( $2^{\text {nd }}$ ed.), ButterworthHeinemann

Plöchl, M., Edelmann, J., 2007. Driver models in automobile dynamics application, Vehicle Syst. Dynamics, 45, 699-741.

Poussot-Vassal, C., Sename, O., Dugard, L., Gaspar, P., Szaboc, Z., Bokor, J., 2011. Attitude and handling improvements through gain-scheduled suspensions and brakes control, Control Eng. Practice, 19, 252-263.

Poussot-Vassal, C., Sename, O., Dugard, L., Gaspar, P., Savaresic, S.M., 2011. Vehicle dynamic stability improvements through gain-scheduled steering and braking control, Vehicle Syst. Dynamics, 49, 1597-1621.

Rajamani, R., Tan, H-S., Law, B-K., Zhang, W-B., 2000. Demonstration of integrated longitudinal and lateral control for the operation of automated vehicles in platoons, IEEE Trans. Control Syst. Techno., 8, 695-708.

Rathinam, M., Murray, R.M., 1998. Configuration flatness of Lagrangian systems underactuated by one control, SIAM J. Control Optimize., 36, 164-179.

Sira-Ramírez, H., Agrawal, S., 2004. Differentially Flat Systems, Marcel Dekker.

Tanaka, J., Ishida, S., Kawagoe, H., Kondo, S., 2000. Workload of using a driver assistance system, Conf. IEEE Trans. Intel. Transport. Syst. Conf., Dearborn.

Tomizuka, M., Tai, M., Wang, J.Y., Hingwe P., 1999. Automated lane guidance of commercial vehicles, IEEE Int. Conf. Control Appl., Kohala Coast.

Villagra, J., d'Andréa-Novel, B., Choi, S., Fliess, M., Mounier, H., 2009. Robust stop-and-go control strategy: an algebraic approach for non-linear estimation and control, Int. J. Vehicle Autonom. Syst., 7, 270-291. 
Villagra, J., d'Andréa-Novel, B., Fliess, M., Mounier, H., 2011. A diagnosisbased approach for tireroad forces and maximum friction estimation, Control Eng. Practice, 19, 174-184.

Zheng, S., Tang, H., Han, Z., Zhang Y., 2006. Controller design for vehicle stability enhancement, Control Eng. Practice, 14, 1413-1421.

K. Yosida, 1984. Operational Calculus: A Theory of Hyperfunctions (translated from the Japanese), Springer.

\section{Appendix A. Nonlinear four wheels vehicle model equa- tions}

The motions of the Nonlinear four wheels vehicle model are governed by the following equations:

Dynamical model:

Longitudinal, lateral and vertical motions:

$\left\{\begin{array}{l}m\left(\dot{V}_{x}+V_{z} \dot{\theta}-\dot{\psi} V_{y}\right)=m_{s} h \dot{\psi} \phi+\sum_{i=1}^{4} F_{x i} \\ -F_{\text {aeroo }}+m g \sin \left(\phi_{r}-\theta_{r}\right) \\ m\left(\dot{V}_{y}+\dot{\psi} V_{x}-V_{z} \dot{\phi}\right)=-m_{s} h \ddot{\phi}+\sum_{i=1}^{4} F_{y i} \\ -F_{\text {aero }}-m g \sin \left(\theta_{r}-\phi_{r}\right) \cos \left(\phi_{r}-\theta_{r}\right) \\ m\left(\dot{V}_{z}+V_{y} \dot{\phi}-V_{x} \dot{\theta}\right)=F_{z 1}+F_{z 2}+F_{z 3}+F_{z 4}-m g\end{array}\right.$

Roll, pitch and yaw motions:

$\left\{\begin{array}{l}\left(I_{x}+m h^{2}\right) \ddot{\phi}=-m_{s} h\left(\dot{V}_{y}+V_{x} \dot{\psi}\right)+I_{x z} \ddot{\psi} \\ +\left[m_{s} g h-\left(K_{\phi f}+K_{\phi r}\right)\right] \phi-\left(C_{\phi f}+C_{\phi r}\right) \dot{\phi} \\ I_{y} \ddot{\theta}=\left(F_{z 1}+F_{z 2}\right) L_{1}+\left(F_{z 3}+F_{z 4}\right) L_{2}-\sum_{i=1}^{4} h_{i} F_{x i} \\ +\left(I_{z}-I_{x}\right) \dot{\psi} \dot{\phi} \\ I_{z} \ddot{\psi}-I_{x z} \ddot{\phi}=M_{z 1}+M_{z 2}+M_{z 3}+M_{z 4}+\sum_{i=1}^{4} C_{z i}\end{array}\right.$

Wheels rotation motions:

$\left\{\begin{aligned} I_{\omega} \dot{\omega}_{1} & =-R F_{x \omega 1}+T_{\omega 1} \\ I_{\omega} \dot{\omega}_{2} & =-R F_{x \omega 2}+T_{\omega 2} \\ I_{\omega} \dot{\omega}_{3} & =-R F_{x \omega 3}+T_{\omega 3} \\ I_{\omega} \dot{\omega}_{4} & =-R F_{x \omega 4}+T_{\omega 4}\end{aligned}\right.$

kinematics model:

$\left\{\begin{array}{l}\dot{x}=V_{x} \cos \psi-V_{y} \sin \psi \\ \dot{y}=V_{x} \sin \psi+V_{y} \cos \psi\end{array}\right.$

It should be pointed out that the above nonlinear vehicle model expresses the coupling of kinematics, dynamics and tyre which are described in Remark 1.

\section{Appendix A.1. Tyre model}

To obtain a realistic representation of the vehicle behavior and simulate the limit handling situations where the extreme driving situations are present, the coupled nonlinear tyre model of Pacejka (Pacejka, 2006) is used. In this model, the coupling of vertical, longitudinal and lateral motions are taken into account. The following illustrative equations can be used as general expressions for longitudinal and lateral tyre forces:

$$
\left\{\begin{array}{l}
F_{x \omega i}=f_{x}\left(\zeta_{i}, \lambda_{i}, \alpha_{i}, F_{z i}\right) \text { for } i=1, \cdots, 4 \\
F_{y \omega i}=f_{y}\left(\zeta_{i}, \lambda_{i}, \alpha_{i}, F_{z i}\right) \text { for } i=1, \cdots, 4
\end{array}\right.
$$

For different loads, the relationships between lateral tire force and slip angle are given in Figure A.17. These forces are linear for small sideslip angles with constant cornering stiffness coefficients $\left(C_{f}\right.$ and $C_{r}$ ) (see Figure A.17). When the slip angle increases, the lateral tire force behavior becomes nonlinear. These changes are described by transition and saturation regions.
Top view: longitudinal, lateral and yaw motions

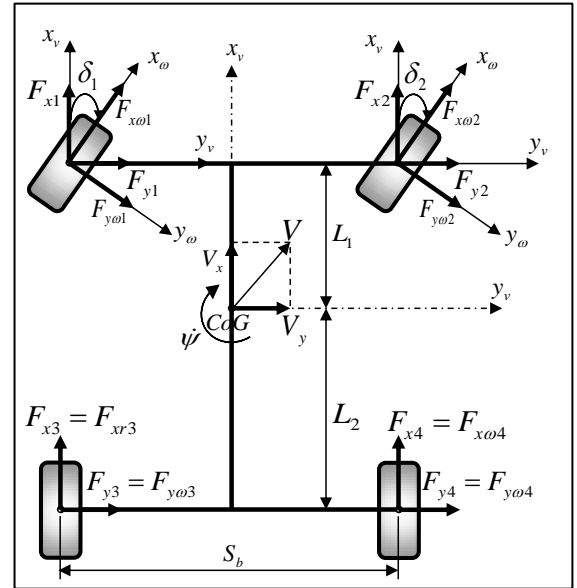

Front view: roll motion

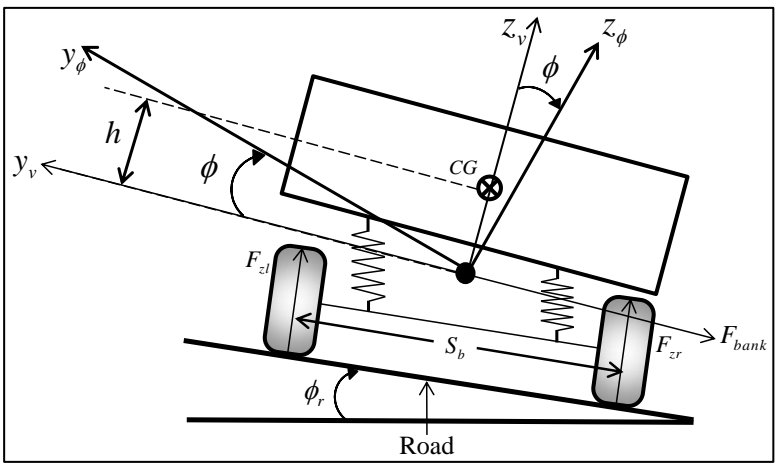

Side view: vertical and pitch motions

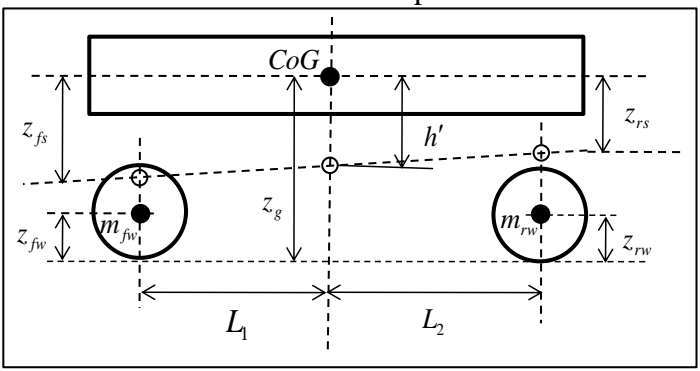

Figure A.16: Nonlinear four wheels vehicle model with roll and pitch motions

In Eq. (A.1), the longitudinal and lateral forces acting on each wheel in the vehicle coordinate system $F_{x i}$ and $F_{y i}$, are related to the tyre forces along the wheel axes, $F_{x \omega i}$ and $F_{y \omega i}$ as follows:

$$
\left(\begin{array}{c}
F_{x i} \\
F_{y i}
\end{array}\right)=\left(\begin{array}{cc}
\cos \delta_{i} & -\sin \delta_{i} \\
\sin \delta_{i} & \cos \delta_{i}
\end{array}\right)\left(\begin{array}{c}
F_{x \omega i} \\
F_{y \omega i}
\end{array}\right)
$$

In this model, the coupling of longitudinal slip ratio $\lambda_{i}$, sideslip $\alpha_{i}$, vertical forces $F_{z i}$ and camber angle $\zeta_{i}$ are taken into account.

\section{Appendix A.2. Vertical forces}

In static situations, the vertical forces are due to the gravitation. During the driving situations the vehicle is subject to transfer loads caused by a coupled motion such as longitudinal acceleration, braking action, cornering situations, roll motion, 


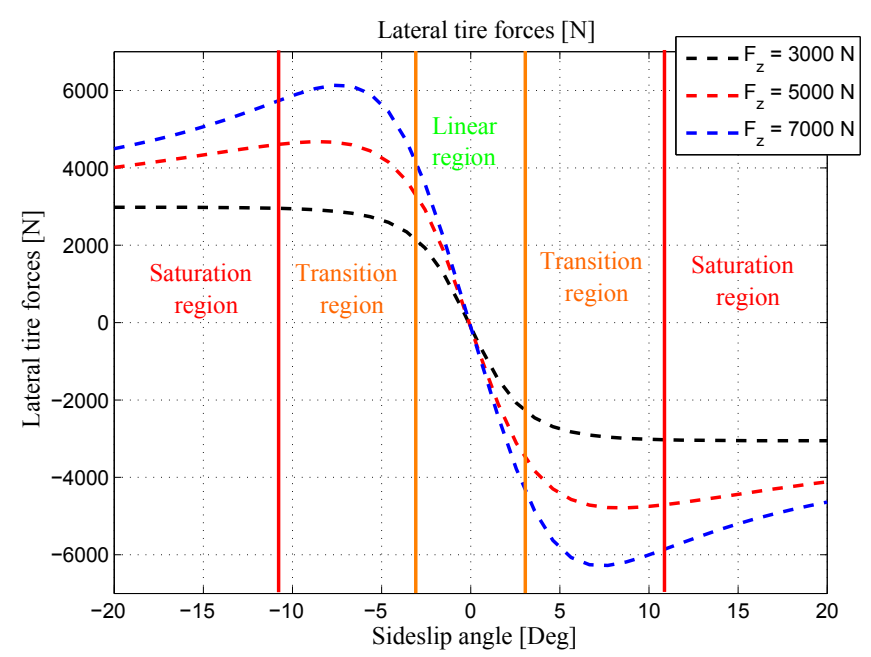

Figure A.17: Pacejka's Model, lateral force for different load and sideslip angle

lateral acceleration, geometry of the road (slope and road bank angles), consequently the vertical forces can be expressed as follows:

$$
\left\{\begin{aligned}
F_{z 1}= & \frac{L_{2} m g \cos \phi_{r} \cos \theta_{r}}{2\left(L_{2}+L_{1}\right)}-\frac{h m a_{x}}{2\left(L_{2}+L_{1}\right)}-\frac{L_{2} h m a_{y}}{S_{b}\left(L_{2}+L_{1}\right)} \\
& -\frac{\left(K_{\phi f} \phi+C_{\phi f} \dot{\phi}\right)}{S_{b}} \\
F_{z 2}= & \frac{L_{2} m g \cos \phi_{r} \cos \theta_{r}}{2\left(L_{2}+L_{1}\right)}-\frac{h m a_{x}}{2\left(L_{2}+L_{1}\right)}+\frac{L_{2} h m a_{y}}{S_{b}\left(L_{2}+L_{1}\right)} \\
& +\frac{\left(K_{\phi f} \phi+C_{\phi f} \dot{\phi}\right)}{S_{b}} \\
F_{z 3}= & \frac{L_{1} m g \cos \phi_{r} \cos \theta_{r}}{2\left(L_{2}+L_{1}\right)}+\frac{h m a_{x}}{2\left(L_{2}+L_{1}\right)}-\frac{L_{1} h m a_{y}}{S_{b}\left(L_{2}+L_{1}\right)} \\
-\frac{\left(K_{\phi r} \phi+C_{\phi r} \dot{\phi}\right)}{S_{b}} & \\
F_{z 4}= & \frac{L_{1} m g \cos \phi_{r} \cos \theta_{r}}{2\left(L_{2}+L_{1}\right)}+\frac{h m a_{x}}{2\left(L_{2}+L_{1}\right)}+\frac{L_{1} h m a_{y}}{S_{b}\left(L_{2}+L_{1}\right)} \\
+ & \frac{\left(K_{\phi r} \phi+C_{\phi r} \dot{\phi}\right)}{S_{b}}
\end{aligned}\right.
$$

It should be noted that the load transfer due to the pitch and the suspension motions are not considered. These equations can be easily obtained using the torque balance construction, an example of the calculation of the vertical forces based on this approach is presented in (Kiencke \& Nielsen, 2004).

\section{Appendix A.3. Sideslip angles}

The nonlinear equations of tire slip angles are:

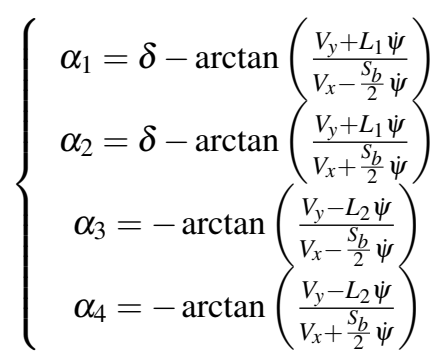

Table A.1: Notations (part I)

\begin{tabular}{l|l}
\hline Symbol & Variable name \\
\hline$\alpha_{i}$ & tyre slip angle $[\mathrm{rad}]$ \\
$\beta$ & sideslip angle at CoG $[\mathrm{rad}]$ \\
$\delta$ & wheel steer angle $[\mathrm{rad}]$ \\
$\lambda_{i}$ & longitudinal slip ratio \\
$\phi, \dot{\phi}$ & roll angle $[\mathrm{rad}]$, roll rate $[\mathrm{rad} / \mathrm{s}]$ \\
$\phi_{r}$ & road bank angle $[\mathrm{rad}]$ \\
$\psi, \dot{\psi}$ & yaw angle $[\mathrm{rad}]$, yaw rate $[\mathrm{rad} / \mathrm{s}]$ \\
$\theta, \dot{\theta}$ & pitch angle $[\mathrm{rad}]$, pitch rate $[\mathrm{rad} / \mathrm{s}]$ \\
$\theta_{r}$ & road slope angle $[\mathrm{rad}]$ \\
$\omega_{i}$ & wheel angular speed of the wheel $i[\mathrm{rad} / \mathrm{s}]$ \\
$\zeta_{i}$ & camber angle $[\mathrm{rad}]$ \\
\hline
\end{tabular}


Table A.2: Notations (part II)

\begin{tabular}{|c|c|}
\hline Symbol & Variable name \\
\hline$a_{x}$ & longitudinal acceleration $\left[\mathrm{m} / \mathrm{s}^{2}\right]$ \\
\hline$a_{y}$ & lateral acceleration $\left[\mathrm{m} / \mathrm{s}^{2}\right]$ \\
\hline$C_{f}$ & front cornering stiffnesses $\left[N \cdot \mathrm{rad}^{-1}\right]$ \\
\hline$C_{\phi f}$ & front suspension roll damping $[\mathrm{Nm} / \mathrm{rads}]$ \\
\hline$C_{\phi r}$ & rear suspension roll damping $[\mathrm{Nm} / \mathrm{rads}]$ \\
\hline CoG & Center of Gravity of vehicle \\
\hline$C_{r}$ & rear cornering stiffnesses $\left[N . \mathrm{rad}^{-1}\right]$ \\
\hline$C_{z i}$ & corrective yaw moments $[\mathrm{Nm}]$ \\
\hline$F_{\text {aeroy }}$ & lateral aerodynamic force $[N]$ \\
\hline$F_{x f}$ & front longitudinal force in the wheel coordinate $[N]$ \\
\hline$F_{x i}$ & $\begin{array}{l}\text { longitudinal tyre forces of the wheel } i \\
\text { in vehicle coordinate system }[N]\end{array}$ \\
\hline$F_{x \omega i}$ & $\begin{array}{l}\text { longitudinal tyre forces of the wheel } i \\
\text { in wheel coordinate system }[N]\end{array}$ \\
\hline$F_{y f}$ & front lateral force in the wheel coordinate $[N]$ \\
\hline$F_{y i}$ & $\begin{array}{l}\text { lateral tyre forces of the wheel } i \\
\text { in vehicle coordinate system }[N]\end{array}$ \\
\hline$F_{y \omega i}$ & $\begin{array}{l}\text { lateral tyre forces of the wheel } i \\
\text { in wheel coordinate system }[N]\end{array}$ \\
\hline$F_{z i}$ & vertical tyre forces of the wheel $i[N]$ \\
\hline$g$ & acceleration due to gravity $\left[\mathrm{m} / \mathrm{s}^{2}\right]$ \\
\hline$h$ & height of the center of gravity $[m]$ \\
\hline$I_{\omega}$ & wheel moment of inertia $\left[\mathrm{kgm}^{2}\right]$ \\
\hline$I_{z}$ & yaw moment of inertia $\left[\mathrm{kg} \cdot \mathrm{m}^{-2}\right]$ \\
\hline$K_{\phi f}$ & front suspension roll stiffness $\left[\mathrm{Nm} / \mathrm{rad}^{1}\right]$ \\
\hline$K_{\phi r}$ & rear suspension roll stiffness $\left[\mathrm{Nm} / \mathrm{rad}^{1}\right]$ \\
\hline$L_{1}$ & distance from the $\mathrm{CoG}$ to the front axle $[\mathrm{m}]$ \\
\hline$L_{2}$ & distance from the CoG to the rear axle $[m]$ \\
\hline$m$ & vehicle mass $[\mathrm{kg}]$ \\
\hline$m_{s}$ & sprung mass of vehicle $[\mathrm{kg}]$ \\
\hline$M_{z}$ & yaw moment $[\mathrm{Nm}]$ \\
\hline$R$ & tyre radius $[m]$ \\
\hline$S_{b}$ & wheel track $[m]$ \\
\hline$T_{b}$ & wheel braking torque $[\mathrm{Nm}]$ \\
\hline$T_{b f}$ & front wheel braking torque $[\mathrm{Nm}]$ \\
\hline$T_{b r}$ & rear wheel braking torques $[\mathrm{Nm}]$ \\
\hline$T_{m}$ & wheel driving torque $[\mathrm{Nm}]$ \\
\hline$T_{\omega}$ & wheel torque $[\mathrm{Nm}]$ \\
\hline$T_{\omega i}$ & driving/braking torque of wheel $i[\mathrm{Nm}]$ \\
\hline$V_{x}$ & longitudinal speed $[\mathrm{km} . \mathrm{h}]$ \\
\hline$V_{y}$ & lateral speed $[\mathrm{km} . \mathrm{h}]$ \\
\hline
\end{tabular}

